\title{
Performing Modularity: \\ Competing Rules, Performative Struggles and the Effect of Organizational Theories on the Organization
}

\author{
Luciana D'Adderio \\ The University of Strathclyde Business School \\ $*$ \\ The Advanced Institute of Management (AIM) Research \\ Luciana.d-adderio@strath.ac.uk \\ \& \\ Neil Pollock \\ The University of Edinburgh \\ Neil.Pollock@ed.ac.uk
}

Forthcoming in Organization Studies

\begin{abstract}
We address the effect of organizational theories on the organization by focusing on how modularity, a widespread and influential organizational theory, performs a modular organization. While scholars have offered opposing arguments for the influence of this theory - i.e. that it either succeeds or fails to 'produce' modular organizations - we show just how and how far modularity is enacted and shapes the organization, and how it may be shaped in turn. Drawing on recent advances in performativity theory we thus contribute to modularity by showing how the modular organization emerges over time as the outcome of performative struggles among competing and complementary theories and how these struggles contribute to modifying the theory and 'designing' organizations. We also add to performativity by theorizing the competition between multiple theories, the emergence of unexpected consequences or 'errors', and their implications for organizational practices and boundaries.
\end{abstract}

\section{Keywords}

Performativity, Modularity, Reliability, Practices and Routines, Materiality, Ethnography

\section{Introduction}

Modularity is a core organizational and management theory which, in the past decade or so, has been adopted and implemented by an increasing number of manufacturing organizations in sectors varying from electronics to automotive. As a theory (Baldwin and Clark, 2000), it has provided the tools to theorize the transition from Chandler's vertically integrated multi-divisional firm (Chandler, 1977) to the vertically specialised corporation characterised by a disintegrated and geographically dispersed value chain (Sanchez and Mahoney, 1996). As a strategy, modularity has allowed firms to organize 
complex products and processes more efficiently (Baldwin and Clark, 1997). According to its proponents, the decomposition of a complex system into discrete sub-systems with loose-coupling and the associated decentralised coordination via standardized interfaces - has helped firms streamline their products and operations, whilst benefiting from autonomous innovation and managing complexity (Sanchez and Mahoney, 1996).

Modularity therefore appears to do more than organize products: in some important respects, it also appears to produce organizations. Precisely how, and to what extent this might be the case, however, has been a matter of contention. With regard to the influence of modularity over the organization, the scholarly debate has seen different positions take hold. Whilst some have emphasized the power of modularity rules to produce modular organizations (Simon, 1962; Henderson and Clark, 1990; Ulrich and Eppinger, 1995; Sanchez and Mahoney, 1996; Baldwin and Clark, 2000; Schilling, 2000; Sturgeon, 2002; Langlois, 2003), others have suggested that this relationship may be more complicated (Brusoni et al., 2001; Chesbrough and Kusunoki, 2001; Takeishi, 2002; Chesbrough, 2003; Hobday, Davies and Prencipe, 2005; Brusoni and Prencipe, 2006). In this latter respect, authors have pointed to the discrepancy between product and organizational architectures and how this is due to contingent factors that ultimately impinge on the ability of modular design rules to bring about modular organizations. This insight has led scholars to argue for the need to look beyond abstract design rules to uncover the additional variables that regulate the fit between product and organizational architectures. Evolving organizational knowledge and skill bases (Brusoni et al., 2001; Chesbrough and Kusunoki, 2001; Takeishi, 2002; Brusoni and Prencipe, 2006), for example, are seen to be amongst the key features that contribute to 'designing' organizations (Brusoni et al., 2001).

Extant approaches to the study of modularity therefore appear to be offering contrasting explanations about the influence of modularity over the organization. Modularity rules, thus, may wield a strong influence such that they produce highly modular, almost Lego-like, organizations (Sanchez and Mahoney, 1996), or they may instead have little or no effect, or even the opposite effect where they may bring about 'non-modular' or even 'integral' organizations (Brusoni and Prencipe, 2006). In capturing some fundamental aspects of how modularity may succeed or fail to produce modular organizations, both schools of thought have implicitly suggested that modularity design rules can potentially have a wide range of effects. In focusing either on the power of modularity rules to produce modular organizations (the mainstream approach), or their failure therein (the contingency approach), however, extant contributions have left the spectrum of intermediate outcomes, modularity's 'performation space' largely under-theorized.

Addressing this gap involves developing a more comprehensive theoretical account of the range of effects of modularity rules over the organization. This includes theorizing the micro-level mechanisms 
that may support or hinder the translation of modular products into modular organizations and how these mechanisms might shift dynamically, in context and over time. This analytic endeavour calls for new ways to conceive of and study modularity not simply as the direct outcome of design and outsourcing strategies, but as a process, that is an effortful, on-going, constantly challenged and negotiated accomplishment. In turn, it entails relinquishing interpretations of modularity as a solid and discrete feature of products and/or organizations, to study it as an emergent phenomenon, one which is deeply and inextricably entangled with the social and material - or sociomaterial - practices that perform it (Barad, 2003; Beunza et al., 2006; Langley and Tsoukas, 2010; Darr and Pinch, 2013). A micro-level, situated and dynamic perspective, we posit, would afford important insights into the study of modularity and the influence of organizational theories more generally.

Studying modularity as an enacted and emergent property of products, technologies and organization is a relevant and timely endeavour which however requires new conceptual tools. Drawing on recent advances in economic sociology (Callon, 1998) and the sociology of finance (MacKenzie, 2006), and related advances in organizational theory (Cabantous and Gond, 2011), we advance a performative perspective on modularity. While building closely on extant mainstream (Baldwin and Clark, 2000) and contingency-based approaches (Brusoni et al., 2001; Brusoni and Prencipe, 2006), this view captures the dynamic relationship between theory and organization in its complexity. Our research questions are as follows: how and how far is modularity performed, in an actual organizational setting and over time? What is the influence of the organizational context on the performation of modularity rules? And what are the wider implications for theorizing the performativity of organizational theories, and the mutual shaping of organizational theories and the organization? We begin by introducing the notion of performativity.

\section{Conceptual background}

\section{The performative effects of theories}

There is an increasing awareness of the links between organizational theories and their 'performative' effects. In recent years, performativity-inspired approaches drawing on practice theory (Suchman, 1987; Schatzki et al., 2001), science and technology studies (Latour, 1987; Pickering, 1995; Callon, 1998; MacKenzie, 2006) and contemporary philosophy (Butler, 1993; Mol, 2005; Barad, 2007) have been gaining increasing recognition in mainstream organizational and management theory (Beunza and Stark, 2004; Ferraro et al., 2005; Cabantous and Gond, 2011).

For instance, authors have described theories as constitutively shaping the design and performance of management practices and institutional arrangements, the social norms that regulate organizational and individual behavior, and the language, categories and assumptions that actors use to interpret the world around them (Ferraro et al., 2005). Further contributions have argued for the need to study 
organizations as sets of relations recurrently performed and reproduced over time and space (Orlikowski and Scott, 2008). According to these authors, organizational boundaries should never be conceptualized as solid or static but as constantly emergent and enacted in recurrent activities (Feldman and Orlikowski, 2011). A similar observation applies to organizational practices or routines: the routines' ostensive - or abstract - pattern can never be taken for granted but needs to be 'brought to life' every time through situated performance and enactment (Pentland and Feldman, 2008).

In this paper we focus on a recent perspective on performativity which has emerged out of studies of economic and financial markets as this, we believe, can provide a particularly useful template for conceptualising the influence of organizational theories. Authors in this stream of work have suggested that theories and models are not simple descriptions of a setting but powerful 'engines' which can profoundly transform the contexts they describe (MacKenzie, 2006). The key tenets of neoclassical economic theory, for example, do not simply describe the economy but are actually being performed within markets (Callon, 1998). Such is the strength of this performation that markets come to resemble the theory. Similarly, the mathematical models that underpin financial derivatives (theory) do not simply rest outside the market (reality) but are a constituent part of it (MacKenzie, 2006, MacKenzie and Millo, 2003). This, however, does not imply that theories are deterministically applied (MacKenzie, 2009). Rather, they are enacted through iterative cycles of 'framing', where theories begin to shape reality, 'overflowing', whereby differences emerge between reality and the theory, and 'reframing', whereby there is again convergence between theory and reality (Callon, 1998). These contributions thus provide the basis for a study of the emergent effect of theories over markets or organizations.

This dynamic approach, we suggest, is especially useful in highlighting how the influence of theories is never complete, and may vary significantly in degrees and levels. MacKenzie (2006), for example, has distinguished between theories that - when they are applied - have no or little observable effect on a setting ('generic' performativity), those that 'make a difference' in some way ('effective performativity'), those that bring about the 'state of affairs' for which they are a good 'empirical description' ('Barnesian performativity'), and, finally, those theories that change economic processes so they conform less well to their depiction by theories ('counter-performativity'). Through foregrounding the dynamic adaptation between theory and reality, performativity can help us account for the nuanced and dynamic effects of modularity, and wider organizational theories, on the organization.

\section{Performativity: Key Notions}

In order to understand how performativity can help us capture the co-production of modularity and the modular organization, we first need to look closer at its language and features. To this purpose we introduce four of its key constructs, starting from the notion of theory. Theories are understood 
broadly as including "[...] formulas, methods, tools and instruments as well as verbal formulations" (MacKenzie et al., 2007:15). In the context of this paper, for example, the dominant theory relates to the organization's imperative to follow a "[...] strategy of modularity [which] entails both belief ("this is the best course open to us") and commitment ("we are going to follow this course") to modularity" (Carliss Baldwin, personal communication). A theory is considered 'successful' (Callon, 2007), or performative, when it brings about the vision of the world contained within.

In order to become performative, a theory or statement has to create a sociomaterial assemblage, or agencement (Callon, 1998), our second key notion. This must contain the theory and all the elements required to realize it (Callon, 2007), including a heterogeneous collection of material features (including technology, texts, and bodies) that "participate in its design, elaboration, experimentation, change, maintenance, extension and operation" (Callon and Caliskan, 2010: 23). Thus for a theory to be performative, it has to involve a heterogeneous configuration of actors and materials that supports its assumptions.

A third key idea, one which is as yet underdeveloped in the literature, is that the effect of a theory can only be decided in relation to other theories. Multiple theories typically coexist at any one time within any organization. Some of these may be complementary, whilst others may compete and clash substantially or irremediably (Callon, 2007). In order to theorize the influence of a theory in its context and over time, we thus need to take a further step and capture how it may operate 'at large', that is in conjunction with other organizational theories and their rules. So far, for example, little is known about " $[\ldots]$ how alternative [theories] compete within organizations $[\ldots]$ through "performative struggles" (Cabantous and Gond, 2011: 582) and "influence behaviours and outcomes" (Cabantous et al., 2014). In the case of modularity, this includes theorizing the process by which the modular organization emerges over time and the (organizational and contextual) sociomaterial dynamics that underpin its inner workings.

The point about sociomateriality takes us to a final key tenet. In a context where multiple statements struggle to establish themselves, one at the expense of the other, the potential of a theory to gather strength and prevail is closely related to its ability to involve not only actors but also artifacts and material devices (i.e. texts, documents, technologies). For example, by delegating their objectives and views as 'scripts' (Akrich, 1992) to stable, durable and visible artifacts such as software, flowcharts or computer systems, actors might, at least in principle, be able to reinforce their own views and objectives over those of other agencies (i.e. organizational communities, functions or teams) that are not so well equipped (Callon and Muniesa, 2005). Performativity therefore provides opportunities to theorize the sociomaterial mechanisms that underpin the co-evolution of organizational theories and the organization. 


\section{Methods}

\section{Research context}

To capture the influence of modularity theory over the modular organization we draw from an indepth, longitudinal study of a pioneering electronics manufacturing firm - an early producer of workstations, storage and high-end computer servers - whose history has been interwoven with the history of modularity in important ways. As part of our investigation, we were able to establish the presence of close historical links between this company and modularity theory from the early years when this company was a fast-rising high-technology start up. Sources report how the pioneering methods used by this organization to manage its design and production activities had generated an early interest in management scholars towards understanding the laws that underpinned modularity and its principles, therefore directly inspiring the ground-breaking Harvard research on modularity (Russell, 2012). From the beginning, in the early 1980s, the company pursued modularity as an efficiency-seeking strategy aimed at streamlining and standardizing products and operations. The firm's progressive vision of modularity, which supported at the same time superior performance and cost efficiencies, by mixing and matching standardized third-party components, allowed it to "solv[e] a critical paradox of computing" (Baldwin and Clark, 2000). This "open systems strategy" (company archives) in turn gave the company outstanding advantage over those competitors which were following more conventional 'closed' trajectories (West, 2003).

A relentless faith in modularity distinguished the company from its competitors from the outset. Everything in their system was modular, "[...] from the lowest level circuits within microprocessors to the highest level system software and application programmes. Its products could be connected easily to one another and other systems, like so many digital tinker toys" (company press archive). The company's flamboyant CEO was himself a strong advocate of modularity. In his public speeches he often drew from the Lego metaphor, the shorthand for modularity, by comparing their products to “[...] a car built out of Lego blocks that [will] all fit together very nicely, and if you don't like [our component], take that Lego block out and put [a competitor's module] in it" (ibid). From the early 1980s, therefore, and throughout the company's phenomenal hike up the electronics industry ranks for the rest of the 1980s and the 1990s, the company's belief in the power of modularity appeared unshakable.

The emphasis on modularity remained strong even when, during the mid-nineties, the company switched from building only workstations - aimed at the expert engineering user who could independently resolve any reliability issues that might have arisen - to high-end enterprise servers aimed at the less competent corporate end user. The acquisition of a new server product line, purchased through a multi-million dollar deal that had made the history of computing, had in fact 
highlighted potential tensions between modularity and the further rationale of 'reliability'. Reliability appeared to gain relevance in a server context, where computers are used to run mission-critical activities in organizations such as hospitals, banks and internet service providers, which are unable to tolerate any significant server downtime. Reliability thus threatened to challenge modularity's so far uncontested dominance in the company strategy, vision and value set.

Even the acquisition of the new server product line (including the very same server which is the focus of this study), and the new reliability ethos supported by the various management and computer experts that had come across with it, however, did not dampen the company's enthusiasm towards modularity. Modularity made mixing and matching components appear a straightforward activity which was unlikely to bear any repercussions on the performance of other components or on the system as a whole (Fleming and Sorenson, 2001). Modularity and reliability were thus not considered incompatible as, in a modular product, any errors and defects detected during testing could be, at least in theory, 'swapped out' of the system simply by replacing any failed standardized modular components with new ones (Baldwin and Clark, 2000). According to our practitioners this principle applied to workstations as much as servers, the latter simply requiring more extensive testing compared to the former, in order to detect and swap any potentially defective components.

Modularity and reliability thus appeared (initially at least) to happily coexist side by side. The company's CEO illustrated the supposedly harmonious relationship between reliability and modularity in computers in a speech when he stated: "Imagine if I had an airplane hangar at home, I designed my own plane from different parts, and I told you to fly it. It wouldn't be safe, yet that's what we're doing" (press archives). Encouraged by this high-level rhetoric which acknowledged the importance of reliability but at the same time relegated it to the background, the company basked in the certainty that modularity would continue to reign unchallenged. And reign it did - at least for another few years.

Between the end of the 1990s and the beginning of the new century the electronics sector bubble finally burst. We were already working on site when the company began to realize that profit margins were significantly shrinking. The effect of the crisis was to create a strong drive towards further efficiency/cost cutting which was to be achieved through modularity and further standardization. The CEO, at this point, predicted “[...] a 'massive standardization' in the way technology is deployed and developed" (press archive). This move was supported by an even greater emphasis on modularity, not only at the product but also at the organizational level which provided greater flexibility to switch suppliers to acquire the latest innovations and best practice. This also allowed increasingly delegating production and testing activities for (both non-core and core but non-critical) components to external manufacturers thus relinquishing responsibility for component-level faults and avoiding the costs of 
repair. It is therefore during this period that the company's belief in the power of modularity began to take hold even further. Modularity, and the associated quest for superior efficiencies, was going to lead them out of the crisis.

In the spectrum spanning from integrality to modularity, they therefore set out to place themselves at the far modularity end by adopting a totally 'disintegrated' organizational structure (something which however they were never fully able to realize, as we discuss later). They intended to achieve this by becoming the 'perfectly modular' organization. This involved focusing on one or few core modules and activities and co-ordinating the rest through arm's length transactions (Campagnolo and Camuffo, 2009). The principle behind this involved buying rather than making: they would no longer need to be manufacturers but would become perfect integrators (Hobday et al., 2005) focusing their capabilities on assembling computers out of third party components. It was precisely at this time that the 'rework and repair' process for one of their server system's core components, the computer board that is the focus of this study, was outsourced to its external manufacturer.

The drive towards standardization/efficiency thus seemed inexorable. Further down at the organizational level, this involved an increased push towards "standardised work procedures (across departments and business units) and documented steps, the presence of electronic databases, and procedures and systems for transferring knowledge across projects and business units" (Campagnolo and Camuffo, 2009: 276). As part of this, the company started looking for additional efficiencybearing strategies which would allow production costs to be reduced while further streamlining their processes. The 'zero inventory' philosophy, for example, which includes the Autoswap system which we discuss later, involved introducing new IT-based lean tools that would allow them to substantially reduce inventory overheads. It was not yet evident at this stage that the increasing emphasis on efficiency, supported by product and organizational modularity and complementary inventory rules, could conflict with reliability with important consequences for the organization.

In the sections that follow we analyze the rise and fall of modularity within and beyond the boundaries of this outstanding organization. In so doing, we focus on the performation of modularity and complementary efficiency-bearing rules and their confrontation with the competing rules underpinning the philosophy of reliability. Through an in depth case study focusing on the changes that occurred in context and over time to the board rework and repair process we theorize how and how far modularity was able to prevail over reliability and produce a modular organization.

\section{Data collection and analysis}

Exploring the contrasting forces that drive towards - or away from - the modularization of product and organization requires the close observation of organizational processes to identify changes occurring 
to product, technology and organizational interfaces. To this purpose we draw inspiration from the notion of an 'artifact's biography' (Appadurai, 1986; Pollock \& Williams, 2009) which consists in following the key stages of a technology's life-cycle and the practices and routines that surround it, as they develop over time and across contexts. Drawing on the biographical approach, we mapped the changes occurring to the computer board rework and repair routine over time, as rework was outsourced and later on re-insourced. To this purpose, we followed the rework routine at different stages to see how this changed as a consequence of the rework being conducted in-house or at the supplier's premises. This entailed 'following the board around' as it crossed the boundaries between supplier and integrator in a typical repair cycle. The biographical approach provided us with insights into modularity and its innermost workings, including how it might affect the emergence of organizational boundaries.

\section{Participant-observation}

Our evidence, based on the detailed observation of production and testing operations at an electronics manufacturer, was gathered during a wider three-year ethnographic study during which the first author was a resident researcher. Direct, daily observation revealed the micro-level, situated organizational dynamics by which modularity was performed, thus providing the basis for a rich 'ethnography of modularity'. Throughout that period, the researcher enjoyed privileged resident status, involving open access to people and facilities for the purpose of observation and interviews. This comprised access to meetings, including those involving suppliers (face-to-face, telephone- and video-conferences and online). The quality and extent of access allowed us to capture in detail the rework and repair (Orr, 1990; Pentland, 1992) routine as it unfolded in space and time (Balogun and Johnson, 2004).

\section{Semi-structured interviews}

Interviews were conducted at the manufacturer's premises with practitioners operating at different organizational levels, sites and functions. Additional interviews were conducted with supplier representatives whilst on visit at the integrator's premises, as well as with resident suppliers 'permanently' situated in a dedicated and clearly demarcated section of the shop floor. Due to the idiosyncratic, situated and highly technical nature of interviews, there was no unified, standard protocol. Interviews were instead tailored to specific issues, project stages, portions of the process, and individual respondents (taking into account their organizational rank and expertise).

\section{Company databases and archives}

Additional longitudinal data relating to periods preceding our direct involvement on site was gathered by accessing the company's internal archives. Crucially, our researcher was also assigned a place within the organizational hierarchy (seven handshakes from the CEO) which came with a corporate digital ID card and email account. These allowed 'anywhere and anytime' remote access to company data and archives, including the opportunity to subscribe to internal alias lists. This proved instrumental for capturing both internal and external exchanges (i.e. across functions, teams and the 
integrator/supplier boundary). The data obtained through direct observation and participation in company's activities was integrated with in-depth, semi-structured interviews conducted across most organizational functions and levels.

\section{Data Analysis}

The data analysis and coding was undertaken jointly by both authors. The first author, acting as the 'insider', was able to draw upon the substantial knowledge and expertise acquired through her extended engagement with the research site to formulate possible explanations. The second author, acting as the 'outsider', played as the devil's advocate (Rerup and Feldman, 2011) in challenging those emerging explanations. The second author also contributed towards analysing the data by proposing explanations that were either accepted or refuted by the first author, based on her intimate knowledge of the field (ibid).

Alongside this dialectical role play we proceeded to analyze the data consistently with an inductive, 'grounded theorising' approach (Glaser and Strauss, 1967). This involved proceeding in an iterative manner, scanning the extensive field data for recurrent concepts and themes, consolidating these into emergent categories (Nag et al., 2007), and subsequently evolving categories through constant comparison with related notions in the extant theory. This process led to developing new concepts, themes and dimensions, which captured how modularity was performed over time and within the context of the rework process.

Through applying the techniques of content analysis (Krippendorff, 2003) and constant comparison (Glaser and Strauss 1967) we were able to identify a number of emerging first-order codes (Van Maanen, 1979). Initially, notions surfacing from the observation of the rework process and interview transcripts revolved around concepts such as "swapping", "modular products", "interchangeable components", "a flexible organization", “mix and match", “open interfaces”, “delegating responsibility" and "the organization as a Lego system". At a later stage, alternative notions begun to take hold. These revolved around concepts such as "fixing", "fault-finding", "a reliable product", "an error-free organization", "debugging", "errors", "quality as a top priority", "we must never fail”, "owning the problem", and "failure-is-not-an-option". Further axial comparison (Strauss and Corbin, 1990) between and across the codes revealed that these converged around two main patterns, which, using the informants' labels (Van Maanen, 1979) we coded as "swapping" and "fixing".

The juxtaposition of these emergent categories with those in the relevant literature produced a crucial discovery: each set of concepts ("swapping" or "fixing") was largely consistent with the rules and assumptions typical of a specific organizational theory, modularity or reliability, as it may be played out in an actual organizational context. Put in other words, our sets of first-order concepts pointed to the fact that the principles of modularity and reliability theory were distinctly at work within the 
rework process, as highlighted by the fact that their rules and their effects were being constantly invoked during the course of everyday actions and discourses. This creative - but firmly grounded leap (Suddaby, 2006) allowed us to "lift" our first-order codes to a more abstract level and led to coding (modularity and reliability) rules and errors as second-order themes. In addition, field quotes also showed how rules were supported by being embodied, embedded and enacted (Martha Feldman, personal communication) in and through heterogeneous ensembles of artifacts and communities which appeared to exert a key influence over the rework process and its outcomes. This led us to code artifacts and communities as further second-order codes.

Constant immersion in the data (Langley, 1999) combined with comparison against the extant literature allowed us to take our analysis to a further level of abstraction. As the evidence clearly indicated, modularity and reliability rules were not simply nominally present, but were being enacted and were shaping the rework process. This, in turn, suggested that modularity and reliability theory and their assumptions were having an effect on the process. The second creative leap in our analysis thus involved the realization that capturing the patterns emerging from the field required a framework able to explain the effect of organizational theories over organizational processes. Our search for a 'theory of theories' or 'meta-theory' led us to engage with performativity theory's emergent constructs. This insight led us to characterize the effect of the rules and errors over the rework process in terms of "framing" and "overflowing" (Callon, 1998) and the influence of theories on the rework process as "performing" (our overarching dimension). This process led to developing a new framework which theorizes how modularity was performed over time within the context of rework.

Finally, further examination of interview and observation data confirmed that the balance of power between the two theories was unstable. This was highlighted by the fact that terms pointing to "fixing" or "swapping" were alternatively gaining and losing emphasis over time. Following these key insights, we were able to identify three temporal stages which captured the co-performation of modularity and reliability over time and within the board the repair cycle: Stage 1- swapping prevailed almost unquestioned whilst fixing remained in the background; Stage 2- swapping and fixing were opposing each other in every aspect and at every level of the rework cycle; and Stage 3swapping prevailed once again but this time was modified.

While drawing on a single case, our findings afford further generalizable insights about the complex relationship between modularity theory and the modular organization, and, more in general, organizational theories and the organization. Powerful generalisations (Siggelkow, 2007; Feldman and Orlikowski, 2011) can in fact result from combining strong inductive theorizing with a practice perspective (Schatzki et al., 2001) based on performativity theory (Callon, 1998; MacKenzie, 2006), which involves embracing the complexity and ambiguity of organizational life and emphasizing its 
multiplicity and emergence. A deeply grounded inductive approach drawing on in depth and longitudinal case study evidence can therefore provide fertile terrain for theory development.

\section{Performing modularity in the board repair cycle}

\section{The biography of a computer board}

To capture the influence of modularity and its rules we draw from the detailed study of the computer board 'rework and repair' cycle. A computer printed circuit board is a flat insulating sheet to which integrated circuits and other components are attached and is a critical component of the overall computer server system (Soanes and Stevenson, 2005). Servers are complex, customized, highperformance, -quality and -reliability machines that provide essential services across a network of computers. For example they can be used to host databases, files and web email. They are individually configured to contain several printed circuit boards, based on their performance and customer specification. Our server can contain up to thirty-six boards, which can perform together or as thirtysix individual computers.

There are several reasons why a board might fail: it can contain fabrication defects, it can become damaged during transportation, or it can be accidentally broken through manual or robot handling in the factory. Whatever the source of failure, this has to be identified and corrected. Repair must be followed by thorough tests to verify that the fault has been fixed. Undetected board-level faults are in fact likely to generate system failures that can occur at any stages of the product life-cycle.

While being a crucial aspect of high-end server production, the fault-finding and bug-fixing process appears at first sight to be rather simple and repetitive. The reality, however, could not be more different. The repair process is situated at the front line of the emergence and persistence of the modular organization, reflecting some of the key tensions that contribute to make an organization truly, or at least partially, modular. This is because it is precisely in this kind of context that organizational processes and boundaries are typically re-negotiated. In the following sections, we set out to follow the computer board around the rework and repair process, as it unfolds across the boundaries between systems integrator and component supplier.

\section{Stage 1- Modularity 'rules'}

In the early days following the acquisition of the server division from an outstanding competitor organization whose fate was declining, board rework and repair activities were conducted in-house, in a dedicated portion of the shop floor known as the 'Failure Analysis' (FA) area. Here, specialist tools and training were made available to technicians to ensure that repairs were conducted in a focused and timely manner. This all changed following the onset of the downturn in the electronics industry. Fully 
embracing a modular production strategy led our firm to focus on systems design and integration, while mostly delegating the production of specialist product components (including computer boards) to their external manufacturers. This provided the organization with the increased flexibility to switch suppliers, as well as increasing or decreasing production following the fluctuations in demand that are typical of this sector (Sanchez and Mahoney, 1996; Sturgeon, 2002), especially at a time of crisis.

There was another consequence to the modularization of production and production-related knowledge, one that is mostly unacknowledged in the extant literature which locates product testing activities entirely within the boundaries of the systems integrator organization (ibid). Following the outsourcing of board production, key problem-solving routines such as fault-finding and failure recovery, which had been until then conducted in-house, had become distributed across the integrator/supplier boundary. This generated some important implications which we identify by examining the computer board's rework and repair cycle at the time of fieldwork (Figure 1).

Insert Figure 1 about here

A computer board is produced at the supplier's facility where it undergoes basic testing. It is then shipped to the systems integrator where it is put through further advanced testing trials. When a fault is found and a board needs to be repaired (or reworked, in technical jargon) it is sent back to the supplier which then issues a new board and sends it to the integrator in exchange for the defective one. The supplier repairs the defective board and sends it out again to the integrator as a new board, as further requests for materials come through. Once it arrives at the integrator, the repaired board is once again scanned and put through the testing process. This process, as observed at the time of fieldwork, appeared to be in all respects very efficient and straightforward. This was until the day in which a rather low key and seemingly harmless email was circulated around the organization.

\section{"No closed loop on the Failure Root Cause"}

The email below came from a Senior Manager from another production site, who was about to join the facility to lead the product engineering aspect of a large transition project.

Date: Fri, 14 Jun 16:58:31 -0700 (PDT)

From: Lead Product Engineer Lead.Engineer@ComputerCo.com

Subject: Re: Localised Rework

To: TransferTeamAlias@ComputerCo.com

I would like to discuss doing in-house rework on [server family name] products in [your manufacturing location]. [...]

[Right now, at your site] there [seems to be] no closed loop on the Failure Root Cause to update the tech's understanding of the failures. [...]

I am actually going to forward some of this discussion to the FINAO managers' alias. I think this will be a topic at the project review next Monday.

Lead Product Engineer 
The email was written in response to an earlier message by the site's Principal Supplier Engineer, which included data about localised rework on the servers' board assemblies at the site. The Lead Engineer's email was addressed to the Transfer Project Operations Team and subsequently forwarded to the "Failure Is Not An Option" (FINAO) Management alias list. The FINAO team, at the time, was involved in key decisions regarding which aspects of server production had to be harmonized across the different production sites. As the name indicates, the team had a mandate to ensure that the production process and its key outputs (computer servers) were reliably similar across sites. Such coordination was required to ensure that products coming out of different factories around the world would meet the same cost, performance, quality, lead-time and reliability specifications. This, in turn, involved selecting which processes, tools, materials and organizations had to be aligned across locations and which could be allowed to differ. The rework and repair process was one of those key areas which, at the time, were under scrutiny.

The FINAO Team, perhaps unsurprisingly given its mandate, responded promptly to this call which was highlighting a potential loss of reliability in the rework area. The FINAO alias list included the first author, who at the time was a resident researcher monitoring the transfer project. In response to the email, the Team began to pull rework/failure data out of the Quality function. Data appeared to suggest that there was "[...] a [statistically significant] population of boards that keeps coming back from the vendor and does not get repaired" (Quality Director's email).

At the same time, the Lead Engineer began to gather data from his production site to support his hypothesis. Data here showed that "[...] the production line in [his manufacturing site] is moving toward in-house rework, rather than away from it" (Lead Engineer's email). At the FINAO meeting, the following Monday, it was agreed that there was sufficient evidence of potential reliability losses to assign a budget and a task team and begin an investigation aimed at uncovering and rectifying the potential reliability issues. Our researcher decided at that point that the topic was sufficiently relevant to the purpose of her study to dedicate part of her time to monitor closely the efforts of the investigation team. In a short time frame, therefore, an entirely new network had been mobilized. This network was built around the notion of reliability and would soon present a serious challenge to modularity rules and their network.

\section{Stage 2 - The investigation: Reliability gains strength}

The investigation analyzed the rework process in the greatest detail and produced a report summarising the outcomes. Findings confirmed that, within the rework cycle, there were instances where the integrity of information and data flows broke down. This carried significant implications for problem-solving and learning processes, as it created opportunities for faults within the boards to 
escape detection. In the following section we consider in detail the main issues at play within the rework cycle as exposed by the investigation.

\section{The board's loss of history and identity}

One of the investigation's key findings highlighted an issue with how the boards' identities were managed. When a board undergoing testing at the integrator was found to be faulty, it was taken out of the production sequence and sent back to the supplier for repair. There it was repaired, re-serialised and eventually sent back to the integrator as a fresh new board. The term 'fresh' indicated that the board was considered 'as new', as it had never been faulty. The rationale behind the re-serialization was the systems integrator's need to avoid the overheads involved in retaining a board's history. This was supported by the Materials function: "If [...] we find that the material [is] defective, then the expectation would be that we return that material to the supplier" (Head of Materials).

This logic, however, was not without implications. The board's new identity, its new serial number, would later prevent recalling its failure history, including all the data pertaining to failures and subsequent repairs. The re-serialisation also meant that, in absence of failure history, the integrator would be unable to learn from its own mistakes or the supplier's. By re-serializing and treating the modules as fully interchangeable despite previous failures, the integrator was favoring "swapping" over "fixing". This, in turn, generated an error of the fixing kind: the loss of failure and repair history.

\section{"Zero Inventory" system and “Autoswap"}

Another key aspect of the investigation concerned the Autoswap process, a formal procedure associated with the efficiency-bearing principles of lean inventory systems, "Lean Production" and "Just-In-Time". These established management practices are known means of reducing the costs and risks associated with holding large stocks of inventory (Adler et al., 1999), costs which can be extremely high in the electronics sector. To reduce its costs, our integrator strived to hold the lowest possible stocks of inventory (a device also known as "zero inventory").

Following this philosophy, our organization had set up a streamlined Inventory Control System managed through Enterprise Resource Planning (ERP) software and Oracle StarBase, a database used to control materials and transactions at each stage of the inventory lifecycle. The software-embedded planning system required that every time a faulty board was returned to the vendor for repair, this would immediately issue a new board and ship it to the integrator. This process was known as 'Autoswap': through the automatic swap of a faulty board for a new one, the levels of inventory at the integrator always remained constant. This eliminated the need for counting boards, and therefore greatly reduced inventory carrying costs: 
Autoswap is an Inventory Management System: I give you a board, you give me a board, I still have the same number of boards in my inventory. And you don't have to say 'I am giving you a board back, now I have to decrement my inventory' until it gets back to me and then I put it back again [...]

Autoswap saves a lot of internal transactions, it is like balancing your cheque book: do I have to trace every penny that went in so that it gets back to me or do I just say in the end I have got the right amount of dollars (Product Engineer).

Their quest for efficiency and leanness was also reflected in the configuration of the software itself. While some aspects of inventory control such as Master Scheduling (planning for the acquisition of production materials) were supported through the purchase of dedicated ERP software modules, others, including Cycle Counting (techniques for organizing physical counting), were not.

[...] you'll find that, depending on which department you are in you may be lucky and have a modern ERP module or you can be frustrated because your particular field of interest is not really seen as the core work. And the core work on the ERP side of things is in terms of MRP, Materials Planning, Master Scheduling, etc. [...] not the inventory (Inventory Controller).

Our Inventory Controller, whose mandate involved preserving inventory accuracy and integrity, did not share the lean 'zero inventory' philosophy embedded in the inventory system (reducing counting overheads). He argued instead for a more sophisticated system that would allow tracking and counting materials. Counting, however, was entirely against the automatic swapping system's lean philosophy and thus was not supported. While therefore greater quality control could have been achieved by acquiring further software capability enabling the counting, these resources were not made available.

Resources were instead clearly aligned with the "Autoswap" methodology, as reflected in the choice of software modules, and clearly favored "swapping" (not counting boards) over "fixing" (keeping track of failed boards). This indicated that the "swapping" imperative, this time combined with a "lean production' efficiency-bearing rationale, was prevailing within the Inventory aspect of the rework. An emphasis on "swapping", the automatic exchange of boards with the vendor, in turn implied a fixing type of error: not counting meant that they were not tracking boards, again leading to the loss of repair history. The organization as a result was extremely lean and run very efficiently, but potentially at the expense of quality and reliability.

\section{Ownership and responsibility}

A further issue found by the investigation was the integrator's inability - and, perhaps most importantly, unwillingness - to track boards that it did not 'own'. When our integrator returned a board to the supplier, it fully relinquished ownership of the component, thus entirely avoiding taking responsibility for its repair, and being held accountable for the damage. This, however, implied a loss of access to crucial repair-related information which remained with the supplier. Combined with the absence of any links between the systems integrator and the supplier's databases, this meant that it was impossible for the integrator to keep track of what happened to a board once it left its premises. 
As practitioners set out to explore possible ways to solve this problem, they faced a number of obstacles. It was clear that the problem could not have been fixed, for example, by simply improving information sharing across the supplier/producer boundary. Both supplier and integrator were in fact against the prospect of sharing any confidential and proprietary data as they saw each other as potential direct competitors. Another possibility would have been to invest in component-tagging technology (radio frequency identification, or RFID), for which the integrator is a world-leading producer. This strategy, however, would have gone entirely against the "swapping" philosophy, which was about not having to count and track boards. The rationale was that the savings procured by RFID would have been offset by even greater inventory and infrastructure costs.

There was yet another reason, however, behind the integrator's reluctance to own damaged boards. Tracking and tracing would have forced our firm to take responsibility for damaged boards, thus removing one of the main potential benefits of modularity and outsourcing. Tagging would have caused the integrator to incur the costs for repairing all the boards that it damaged, rather than simply returning them to the supplier: “[ ...] with Autoswap we don't have to track by serial number, where did it go, and if a board gets scratched or damaged [here] the vendor buys that board and we don't ever have to see it again" (Product Engineer).

Once again, they were "swapping", while relegating "fixing" to the back stage. Swapping allowed the integrator greater flexibility in switching both components and their suppliers. This was based on establishing an arm's length relationship with suppliers, supported by a clear division of ownership and responsibility. Advanced IT-based technologies such as RFID, which could have supported component traceability, were thus not invoked as they were against the main "swapping" philosophy. A fixing-type error was generated also in this case: their emphasis on "shifting" the problem to the supplier instead of "fixing", combined with their unwillingness to track what happened afterwards, meant that they also lost access to crucial repair-related information. The contradiction was that, whereas their intention was to "lose" the failed board, they were instead very likely to see it again, only in the different, unrecognisable guise of a fresh, re-serialised board.

\section{Asymmetries: system vs. component view}

Another key finding of the investigation concerned the way competences were divided across the supplier/integrator boundary. The combination of modular and outsourcing strategies in fact implied a clean cut division of labour and competences. This generated strong knowledge, views and capabilities asymmetries between producer and supplier (Simon, 1996; Marengo et al., 2005; Brusoni et al., 2001). These were clearly apparent in the area of testing. 
While in fact the integrator held both component and system testing capabilities, the supplier was only proficient at basic component testing. The supplier was therefore often unable to detect - and thus repair - any faults caused by the systemic interactions between the board and other components. According to a Product Engineer, "[...] Because of the way we designed our test process, the external manufacturer is not able to catch performance problems [...]. We didn't give them the extensive kinds of testing and the expensive equipment in order to do the functional level testing [...]. That is actually left here". At the system integrator,

We run 'exercisers' kind of tests. So we put a board into a system and we run tests on that. We also run $[\ldots]$, diagnostic $[\ldots]$ and memory tests of different sorts. The requirement for most of those tests is that you actually have a running system, you have enough hardware around there to really start up a system under Unix and, [...] in order to do that, you need a 'hot mark-up'. So you need a test bed that has all the different pieces of the system in order to put the board in and make it run. (ibid)

This indicated that the level of system testing capability at the supplier was low, an asymmetry that could have been tackled by sharing the system testing capabilities with the external manufacturers: "[Suppliers] are moving into more and more testing but [...] to do the kind of functional level testing that we do you have to know a lot about the system: how [it] was designed, what the architecture is, and all the intricacies and details behind it" (Lead Product Engineer).The systems integration testing, instead, is a core capability for the integrator:

So it's a kind of strategic advantage, strategic capability that we have [...] these high end systems, this is our bread and butter, this is where our technical strength is, so we want to make sure that they are tested well, everything works and all that [...]. Assembly is not where the value added is for us: it's the integration of the system. So [it's about] the system level testing, and the testing of the sub parts and making that into a working system and making sure that all those things do work together, that you find as many problems as you can. [Besides,] we designed it and it is one of our competences right now [ibid, emphasis in the original].

Establishing a clear separation between system and component testing, one of the main consequences of adopting a modular strategy, meant that integrator and supplier had very different views of debugging and failure: one a system-based view, and the other a component-based view. The asymmetry in their views and cognitive frames (March and Simon, 1958; Boland and Tenkasi, 1995; Weick, 1979), knowledge and capabilities (Simon, 1996; Marengo et al., 2005), and access to tools and technologies (Callon and Caliskan, 2010) was reflected in a strong bias in the way they were able to interpret and resolve hardware-related failures. The supplier, having no system testing tools, was unable to judge whether a board was faulty, as they had no means to test the component within the system. The integrator, by contrast, was able to detect system failures and establish whether and how a board was defective. Again, by not giving the suppliers system testing capabilities they were 
favoring "swapping", a clear division of knowledge across the supplier/integrator boundary, over "fixing" and they obtained a fixing kind of error: suppliers were unable to detect systemic failures.

\section{Testing procedures, rules and heuristic}

The investigation also found that both formal rules/procedures and informal heuristics were consistently supporting "swapping" over "fixing". This became apparent when observing everyday practices on the shop floor. With regard to standard procedures, as one would expect from an organization fully committed to a modular strategy, technicians were taught to "swap" (switch and return a failed board to the supplier) rather than attempting to fix. Responsibility for component failure lay entirely with the supplier and this was reflected in the shop floor technicians' low skill profile. Test techs were instructed not to attempt to fix a board as this would only risk damaging it further, thus shifting the responsibility/cost of repair to the integrator.

Even when choosing to bypass formal procedures in favor of informal practices, however, our technicians were still "swapping", not "fixing". Technicians, for example, frequently worked around formal procedures by referring to known local trial and error heuristics based on their tacit knowledge (Narduzzo et al., 2000). An experienced technician presented with a failure would in fact often have a feel for which component had a higher likelihood to be the cause. This for example could be a hunch based on knowledge of the component that most frequently failed. At other times, the server's correct functioning could be assessed by touching the machine to judge its temperature or listening closely to ensure that its hum was consistent with "the sound of a well-tuned machine" (shop floor technician). Once identified the component suspected of causing the failure, the technician would proceed to extract and reject the presumed faulty component without making any further enquiries, and then swap the failed component for a new one. The sequence would be completed by re-testing the system to confirm that the cause of the problem had actually been eliminated.

While effective, however, this heuristic did not allow the test tech to establish the actual cause of failure. According to an Engineer, Failure Analysts (FA) “... do not have a definitive diagnosis of a failing board and they make an educated guess [as to] where the problem lies" (Lead Engineer, emphasis added). It follows that the FA cannot be sure whether the diagnosis is correct: "The feedback on whether [the solution] fixes the problem is not very good at this point" (ibid). This had never been an issue in the past whence failed boards were moved to the nearby FA area where they were diagnosed and fixed, and eventually scanned back into the production line. As a consequence of outsourcing repair to the supplier, however, the opportunity to pinpoint the exact cause of failure had been lost. The board was returned to the supplier with only "[...] an indication as to where the problem lies" (Lead Engineer), thus shifting the responsibility for finding the fault to the 
supplier. As the vendor did not have system test capabilities, however, they were often unable to find the fault.

With Autoswap, the [faulty] board goes to the vendor, there [it] is not repaired (the vendor does not have the system level test capability that we have in the factory) and then the board is returned [to us] in production in the flow of new boards, and often shows up as 'New-To-Fail' (ibid).

As the integrator did not know that the board had previously failed and subsequently undergone repair, "The board [did] not go back to FA for failure validation before being inserted into the production process (ibid, emphasis added). The consequence was that: "Boards could end up in a loop with the FA for difficult-to-diagnose boards because the tech could repeatedly choose the same component for replacement because it has the highest probability of failure". Learning, both at the level of the individual expert and the organization, was severely hindered as failure data could not be used to inform the tech's future interactions with that particular board. Once again, practitioners favored "swapping" (switching and shifting fault-finding to the supplier) and the result was a fixing kind of error: uncertainty about the actual cause of failure.

\section{Interfaces, systemic interactions and performance}

The last key finding of the investigation raised questions about the role of complexity and uncertainty in debugging complex, fully modular server products. Practitioners at the integrator, as explained earlier, were aware of the modularity principles and the organization itself could be described as striving towards full modularity as a goal. Their ambition was a Lego-like situation where they would be able to straightforwardly switch and return components to the supplier ("swapping") without having to fix. As a result of their faith in modularity, our practitioners believed that the clear decoupling of modules within a system should have eliminated the need for system level testing.

Despite the fact that our organization presented a highly codified and standardized environment, however, the hardware debugging process was hampered by high levels of uncertainty and ambiguity. In high-end electronics, the fast pace of innovation combined with frequent imbalances between innovation at the component and system level (Brusoni et al., 2001) meant that problem solving processes such as bug fixing were often only imperfectly decoupled (Marengo et al., 2005). A particularly reflective practitioner raised this issue by voicing the opinion that, in high-end electronics, full modularity was more of an ideal that firms aspired to:

[...] there is another issue right now, between having fully tested sub-components that you can 'mix and match' and put together vs. do we need to test something as a matching set. There is something with the way boards interact that we have to test them, you know, actually set up the material together to make sure that it works together and then not change anything. [...] We would like to get to a commodity level where we could just interchange things without any worry, but that's not exactly 
where we are yet [...] If I know that it has been tested, it always works (Lead Engineer, emphasis added).

In acknowledging these drawbacks our Engineer demonstrated an awareness of the potential limitations of the mainstream modularity paradigm being performed. However, even in his sophisticated vision, he too saw their current situation as a temporary, intermediate step in the path towards full modularity, or the day where they would be able to simply swap, without worrying about fixing (system testing). In the meantime, system-level testing provided the means to detect faulty modules which could then be swapped out in exchange for a new module. In other words they were "fixing" (performing system-level testing which in principle should be redundant in fully modularised systems), despite their enduring belief in the power of swapping, and a swapping-kind of error was generated: boards could not be exchanged unproblematically.

\section{Outcome of the investigation: Vicious Cycle of Failures}

The investigation conducted on the rework and repair cycle thus produced an unexpected outcome: defective boards continued circulating without getting fixed (Figure 1b).

Insert Figure $1 \mathrm{~b}$ about here

Once a (still defective) board arrived at the integrator re-labelled as a new board, shop floor practitioners were unable to recall that the board had previously failed. Because the new identity provided a clean slate, the board was not put through Failure Analysis (where repaired boards should have undergone system level testing for verification), but was instead put once again through production as a new board. Here, the still defective board would almost certainly produce a new fail. Because the board remained the component most likely to have caused the failure, this was once again chosen as candidate for replacement and sent back to the supplier for repair. There it was not repaired, as the supplier did not have system testing capabilities. System level faults did not show up in the supplier's tests and consequently did not get fixed. The board was re-serialised and returned unrepaired to the integrator only to fail again.

These dynamics resulted in a vicious failure cycle of undetected faults and potentially repeated failures: test techs at the integrator did not know what they were swapping, the supplier did not know what they were fixing, the integrator did not know whether the board that arrived from the supplier was new, or, if it was a repaired board, whether it had been actually fixed. A defective loop was generated, whereby boards kept coming back and forth between the integrator and component supplier but remained unrepaired. In the previous context where debugging was performed in-house, this problem had been prevented by an easy and quick route from the production line to the nearby FA area where the board would get repaired and re-tested (Figure 1a). The investigation concluded that an 
element of unpredictability and a source of error had been created as a consequence of bug-fixing having become decoupled across the integrator/supplier boundary.

Insert Figure 1a about here

\section{Stage 3 - Modularity persists but modified}

As highlighted by the investigation, modularity theory, and its key rules and assumptions, were being performed fiercely in almost every aspect of the rework cycle where modularity rules had been able to prevail practically unchallenged. The errors brought up by the investigation, however, were about to produce some dramatic changes. The evidence of potential reliability and quality losses was promptly enrolled by those supporting reliability, whose side began to gain traction. From a reliability viewpoint, it was becoming increasingly clear that modularity and complementary rules had made the organization so efficient that it had become too lean to learn, both from its own and the supplier's errors.

Following the investigation, a new network supporting the reliability argument thus began to emerge. New statistics began to surface that challenged practitioners to reflect on the consequences of undetected failures in production and in the field. Failure information that had once been ignored began to be foregrounded. People in corridors debated the pros and cons of letting errors proliferate uncorrected. Meetings were called which provided opportunities to discuss the possible implications of bringing rework back in-house. At the same time, arguments were being advanced from the modularity side of the debate warning that re-internalizing rework would imply incurring the costs and responsibility of repairing boards which they themselves had not broken, costs which would have normally been incurred by the supplier. These drawbacks, however, appeared less significant compared to the loss of reputation brought about by errors of the 'fixing' kind which could potentially result in substantial outages in the field.

An instance of reliability loss was highlighted during the course of a heated debate around an extended server outage incident which had recently occurred at a Japanese customer running missioncritical manufacturing operations. The outage, which had caused extreme disruption to the customer's time-sensitive shop floor operations, had clearly exposed the risks of server quality and reliability loss. Server failure, in this case, had not only implied unacceptable consequences for the customer itself, which on the basis of that single episode was threatening to rescind the contract, but also for our organization which, following the incident, was facing a significant loss of reputation. During the course of this debate the reliability and modularity coalitions came to confront one another. The reliability side used the example of the outage to support the argument that errors of the kind 
highlighted by the Japanese incident could not be tolerated. The modularity side, instead, tried to dismiss the incident as minor and the customer as unreasonably demanding. The threats and dangers highlighted by the outage episode, however, were very real and therefore not so easy to downplay. This realization caused some practitioners to change sides during the debate, moving across from the modularity to the reliability supporting coalition and thus fomenting the growing momentum in favor of reliability.

The Japanese customer incident, and the related discussions highlighting instances of reliability loss in the server domain, produced therefore the effect of strengthening the outcome of the investigation, thus providing further ammunition for the proponents of reliability who were able to canvass increasing support for their arguments. Once appropriated by a network that was rapidly growing in power and recognition, the evidence of actual and potential server failures uncovered by the investigation and related incidents such as the Japanese outage, could therefore no longer be easily dismissed and called for a solution to be reached concerning the extent of integration in the area of rework. The solution that was reached took the form of a compromise among different views and errors and resulted in re-internalizing a limited portion of the rework, pertaining to some of the most common failure causes for that particular board type (Figure 1a). This solution, which reflected a partial victory for reliability, was supported despite implications for cost (the need to take responsibility for boards damaged on the premises), skills (the requirement to retrain technicians to undertake rework), technical implications (the need to re-acquire tools necessary to perform repair inhouse), and despite the fact that this component was classified as critical, but ultimately non-core.

Yet, the solution did not imply that they were ready to simply abandon modularity. While reliability posed a strong challenge, modularity rules had been successfully entangled with practically every aspect of the rework cycle. They were embedded and enacted in the design of the product and the interfaces, in the software tools and methodologies used to manage inventories, in key aspects of the relationship between integrator and supplier, in the distribution of repair competences and skills, in the philosophy that avoided trust and relinquished control, and finally in both formal and informal shop-floor procedures. All these aspects added to the strength of modularity rules and meant that they were hard to overturn. For example, artifacts like the Oracle database or Autoswap, which was the material embodiment of the "swapping" imperative, were difficult to work around. Even those practitioners who had hinted at possible limitations in performing the ideal modular organization, including the Engineer who circulated the unintentionally incendiary email that set off the investigation, interpreted this just as a temporary setback in the path towards full modularity.

The decision to bring some of the rework back in-house, therefore, must be seen in the light of the predominance of modularity and its rules. The compromise solution did not in fact invalidate the 
theory. Rather, this temporary and partial remedy allowed modularity to continue to be performed (embodied, embedded and enacted) in almost every aspect of the rework process, although in a slightly modified, less perfectly decoupled form. Despite these problems, the practitioners' belief in the power of modularity remained very much alive.

\section{Discussion}

Drawing on our rich data set, we can now proceed to introduce our theoretical framework which will unravel the dynamics through which modularity was performed within and beyond the context of the rework cycle (Fig. 2). This in turn will shed light on the competition between modularity and contrasting theories, and their implications for the mutual shaping of theory and organization.

Insert Figure 2 about here

Our in-depth, longitudinal case study highlighted the coexistence of two main theories attempting to configure the rework process and the wider organization: modularity and reliability. The dominant theory consisted of modularity and a complementary set of efficiency-bearing rules and tools (Zero Inventory and Autoswap). The challenging theory included reliability rules and a complementary set of principles (quality). We find that the competition between modularity and reliability in the rework context involved three phases: initially, modularity prevailed (rework was outsourced to the supplier); then reliability gained strength and clashed with modularity (triggering the investigation); and, finally, a compromise was reached between the two theories and associated sets of rules (following which rework was brought back in-house).

\section{Modularity framing the Rework process (and ensuing errors)}

As illustrated by the company history, modularity had been reigning almost unchallenged within the rework process and the wider organization. The performation of modularity depended upon the realization of a specific set of rules, or 'conditions of felicity' (Austin, 1962; Callon, 2007) which, for modularity to have an effect, had to frame the rework process. Modularity rules included product design rules, which are "[...] principles that define how an artifact works, what it does and how it is manufactured" (Brusoni and Prencipe, 2006: 179) as well as the related organizational principles and properties that are required for the rules to be performed. More specifically, modularity rules included: the modularization of product and organizational architectures, the codification and standardization of product and organizational interfaces, maintaining an arm's length relationship with suppliers, and performing a clear division of knowledge, problem-solving and productive labour, responsibility and accountability across the supplier/producer boundary (see Table 1). 
Insert Table 1 about here

A complementary set of efficiency-bearing rules contributed towards supporting modularity, including the principles of 'Lean' or 'Zero Inventory', and 'Autoswap', regulating the automatic exchange of boards with the supplier. Throughout most of the company history up until the beginning of the observation period (first stage), this complex set of rules appeared to be firmly in place and was effectively framing the process. Over time, however, another competing theory, reliability, had begun to gain momentum.

In the second stage, modularity began to clash with reliability in the rework process. The reliability focus, a consequence of the acquisition of the high-end server product line, had been coexisting for a while alongside modularity and its complementary efficiency-bearing strategies. Following the economic crisis, however, the increasing pressure towards modularity and leanness at both product and organizational levels had led to the outsourcing of rework. Frictions had begun to emerge between modularity and reliability, which culminated with an email being circulated, which exposed important potential instances of reliability loss. Reliability rules required that faults should be detected and traced, errors remedied and failures prevented; boards and all components tracked throughout their life-cycle and system level diagnostics performed at the supplier's premises; knowledge and problem-solving integrated and responsibility and accountability shared with the supplier. A set of quality principles complemented the reliability statement, setting the parameters within which the boards needed to operate to guarantee acceptable failure rates (see Table 1).

Beyond rules, our data shows the emergence of another category of elements: 'errors' (Fig.2). Similar to Callon's 'overflowing' (1998), errors followed from the competition between (temporarily) conflicting theories, modularity and reliability, as a consequence of their joint attempts to frame the rework process. Thus, in the first stage, those actors supporting reliability had drawn on a range of failure statistics and charts to expose how performing modularity was generating errors of the "fixing" kind (boards circulating and not getting fixed). In the second stage, modularity supporters had instead highlighted the possibility that performing reliability might produce "swapping" errors (the integrator would pay for fixing boards that it had not broken). Errors were therefore enrolled in the confrontations between modularity and reliability and helped shape the discussion.

Practitioners soon found themselves negotiating between different theories (modularity or reliability) and their (actual or potential) errors. For example, fixing errors were promptly enrolled as evidence of the drawbacks of modularity by actors supporting reliability and were used to strengthen their claims against the prevailing theory. Negotiations led to a compromise in the third stage, where modularity 
prevailed but was modified. Reliability, nevertheless, had at least partially succeeded in highlighting and problematizing the errors created by modularity, to the extent that practitioners decided to take action. The decision to change the organizational boundaries to re-insource aspects of rework represented a partial victory for reliability (partial because the fix ultimately meant that modularity continued to dominate in all other aspects of the rework process).

\section{Performative struggles and materiality}

An important related point is that modularity and reliability rules (and their errors) were able to frame and reframe the rework process by involving a heterogeneous set of material elements (Callon and Caliskan, 2010). Modularity rules, for example, which supported "swapping" (switching and returning a faulty board to the supplier), were embedded in different aspects of the rework process, including tools and technologies (such as the Autoswap system and the Oracle database which together turned the swapping of faulty modules into the default option); were enacted through the participants physical bodies and ostensive understandings of the rework process and its purpose (i.e. 'a swapping routine'); and they were performed through formal procedures and informal heuristics (as in the methodology used by shop floor technicians for diagnosing failed boards). Reliability rules, instead, which supported "fixing" (switching and repairing a failed board in-house), despite being embodied in some of the actors' abstract ostensive understandings of the process (i.e. a 'fixing routine') did not succeed in enrolling the ERP cycle counting module and RFID technology which would have supported counting and the automatic tracking and tracing of boards across the supplier/integrator boundary and along the rework cycle. The extent to which practitioners were able to mobilize social and material features in support of one theory over another helps explain how a theory might begin to dominate in an organization and the consequences for its practices and boundaries.

The battle between contrasting theories can therefore be understood as the confrontation between multiple competing ordering systems (the theories, their rules and the array of sociomaterial elements that support them). Sometimes the ordering systems underpinning a theory, corresponding to different 'logics' (Purdy and Gray, 2009; Greenwood et al., 2011), interpretations, or understandings of the process (Dougherty, 1992; Bechky, 2003; Carlile, 2004) plus the sociomaterial infrastructures that support them (or 'logistics'), may overlap substantially (Berg and Timmermans, 2000). Yet at other times, as our case illustrates, they may be opposing each other to a greater extent. The outcome, in this case, was an "amalgam of logics" (ibid: 43) as exemplified by the compromise between a "swapping" and a "fixing" logic, and the related ostensive understandings of the rework routine, eventually reached in the rework area.

What did this compromise look like and how did it configure the rework process? While modularity, by embedding itself in most aspects of the rework process, had prevailed over reliability and retained 
its dominant position in the rework process, it was clear that the latter had managed to secure at least one crucial victory. The hidden 'fixing errors' that had been highlighted by the performative struggle against reliability, embedded in the material form of failure stats and charts used as the basis for negotiations, had been acknowledged and addressed by bringing rework back in-house. This brought renewed (albeit temporary) stability to the process, as reflected in a renewed balance of power between the two competing theories. Modularity's main rationale, "swapping", was therefore able to continue to thrive, not despite, but because it could draw upon its errors ("fixing").

\section{Organization modifies the theory}

Performative struggles therefore resulted in changes to the organization which became more closelycoupled than the modularity's abstract ideal of a 'perfect integrator' - which our practitioners were pursuing - would have allowed. The outcome of the competition between two theories in the context of the rework process however also implied that modularity itself was modified as a result of the performative struggle against reliability. This particular instance of performation of the theory had challenged - and at least marginally deflated - the company's unwavering faith in the power of modularity. Or, perhaps more precisely, it had suggested that a more sophisticated temporary truce was required at this point in time, in this particular organization, between efficiency- and reliabilitybearing strategies, two important (usually complementary, but in this particular case temporarily conflicting) sides of the lean production philosophy (Womack and Jones, 1996). As a consequence, modularity was therefore still being performed, albeit to a lesser extent. The performative struggles between modularity and reliability over time and in the context of this organization had eventually resulted in the modification of the theory itself.

\section{Conclusions}

In this paper we have considered the effect of organizational theories on the organization by focusing on how modularity, a widespread and influential organizational theory, was able to shape the organization, and how it was shaped in return. We have done so by focusing on how modularity and associated rules were performed, over time and in the context of a contemporary pioneering hightechnology organization, whose history and successes have been closely tied to those of modularity itself. Through a high level of field access which has allowed us to follow the changes occurring to the rework process in detail and over time, we were able to gain valuable new insights into the coproduction of theory and organization.

Drawing on the performativity thesis this paper thus contributes to studies of modularity through a theoretical framework which captures how modularity is performed in context and over time. Our 
framework helps us theorize how the modular organization emerges as the outcome of performative struggles among competing theories (modularity and reliability) and their rules, and how these sociomaterial struggles and the ensuing errors modify the theory and shape the practices and boundaries of the organization. In so doing, we also add to performativity-inspired approaches in economic sociology, the sociology of finance and organizational theory, which have thus far mainly focused on the influence of individual theories, by theorising the competitions between multiple theories, their outcomes, and the implications for organizational practices and boundaries. We conclude by highlighting three core findings that provide the basis for a performative study of modularity and wider organizational theories.

\section{Theories (and their errors) perform organizations}

The first key contribution resulting from studying modularity from a performative perspective is a theoretical framework which captures the more complex, dynamic and nuanced effects of modularity rules on the organization. As our evidence shows, while modularity rules can indeed be fully prescriptive or merely descriptive, they are often performed by actors to different levels and with varying outcomes. We therefore add to those contributions in the modularity literature which have offered opposing arguments for modularity theory - i.e. that it either succeeds or fails to 'design' (Brusoni and Prencipe, 2001) organizations - by showing how and how far the theory is enacted and shapes the organization, and how it may be shaped in return. In our case, the evidence shows that modularity was being performed successfully in most aspects of the rework process. We can therefore place the outcome of performing modularity, in the rework context and during the period of observation, at the 'strong' end of the performativity range (MacKenzie, 2006; D'Adderio, 2008).

At the same time, however, our evidence also shows that the 'translation' (Callon, 1986) of modularity rules into a modular organization was incomplete. In framing the rework process, modularity rules had created errors which were promptly enrolled by the competing paradigm, reliability, and used to modify both the theory and the organization. The re-internalization of a portion of rework, in response to fixing errors, had thus allowed modularity to prevail, albeit in a modified form, marginally closer to the integral than the fully decoupled end of the spectrum. 'Errors' (or, in performativity terms, the overflowing) have been a neglected aspect of modularity studies, having been implicitly viewed as either the outcome of the theory not being fully or correctly implemented into technological and/or organizational interfaces (the mainstream approach); or as the result of the failure of the theory itself to account for organizational and technological complexity (the contingency approach). Through our performative lens, instead, we were able to theorize the emergence of errors not simply as a failure of technology/organization to reproduce the theory or a failure of the theory to reflect the complexity of technology/organization but as the continuously emergent outcome of performative struggles among competing theories in their context. The emphasis on context has also 
provided important insights into the organization's ability (or lack thereof) to harness overflows and use them to reconfigure its boundaries and/or the theory.

In further theorizing the role of errors, our findings also add to performativity-inspired approaches in organizational theory (Cabantous and Gond, 2011), and the discussion of 'overflows' in performativity theory (Callon, 1998). In the first case, our results add to the extant theory by showing precisely how overflows may (or may not) contribute to constituting and modifying organizations and their theories. In the second case, we shed new light over the possible sources of overflows. Whereas the extant theory (ibid) has focused on the emergence of overflows as resulting from 'imperfections' within the frame, we demonstrate that overflows may be at least partially constituted outside the frame, from a theory's interactions with other theories operating within and beyond the organizational context.

\section{Performative struggles shape organizational boundaries}

Our second core contribution therefore consists in theorizing the coexistence of modularity with competing theories, their performative struggles and their implications for the organization and the theory. Our in-depth, longitudinal study set in a contemporary high-technology organization exposed to multiple organizational and institutional pressures showed how modularity did not operate alone but instead coexisted together with other theories which were also attempting to configure the organization at the same time. As our evidence illustrates, within organizations and beyond, theories rarely exist in isolation. Rather, organizations are typically configured by multiple ordering systems, including a plurality of theories, each with its own rules and assumptions. Some theories may be mostly complementary (as, in our case, modularity and zero inventory principles, or reliability and quality), whereas others may be largely in conflict (as the efficiency-bearing modularity rules and reliability). To complicate the picture, alliances among theories may shift quite significantly both over time and in the context where they are enacted.

The presence of competing theories, and their influence over organizational practices and boundaries, has been largely neglected within studies of modularity. Building on the case of a diverse and distributed organization, and drawing on performativity's emphasis on plurality and multiplicity, we were able to add to extant contributions by revealing how different sets of rules do not always merely substitute one another, but often become involved in dynamic confrontations. While at times confrontations can indeed result in the replacement of one rule, which becomes non-performative, for another, which becomes performative (as in Brusoni and Prencipe, 2006), at other times their outcomes tend to reflect a synthesis, involving mutual dynamic adaptation under conditions of uncertainty. Our results therefore add to the modularity debate by theorizing the dynamics underpinning performative struggles (Callon, 2007) and how they shape both theory and organization. In addition, as theories evolve through competition, their influence varies over time and across 
organizations, so that any outcomes can only ever be emergent. It is therefore the dynamic competitions among contrasting theories and their networks, which include but span beyond abstract rules (Sanchez and Mahoney, 1996) and knowledge (Brusoni et al., 2001), which ultimately modify theories and 'design organizations'. While adding to modularity, this finding also responds to the recent call for studying how different "[...] theories interact and influence organizational practices" and shape organizational behaviours and outcomes "[...] through performativity struggles" (Cabantous and Gond, 2011: 582). While Callon (2007) has advocated for the need to re-imagine organizations and markets as sites for performative struggles, “[...] this perspective has yet to be explored" (Cabantous et al., 2014). But what are the micro-level dynamics which define how theories compete?

A related finding is that, to exert its influence, modularity had to build a scaffold, including an array of social and material features (similar to Callon's agencement) which supported the realization of its rules in practice. Modularity and complementary efficiency rules, for example, were so thoroughly embedded in texts, technologies and artifacts that there were serious limitations on how far actors could operate 'outside' the theory. A neglected aspect of current theorizing, capturing the sociomaterial aspect of rules performation, or "[...] how [a] theory is translated into tools and material devices" (Cabantous and Gond, 2011: 583) thus further adds to current explanations for the success of modularity beyond abstract rules and knowledge. A performative framework therefore allows us to capture how the practices and boundaries of the modular organization are continuously challenged and constantly shift to reflect the particular array of (intra- and inter-organizational, social and material) relationships that produces them at any one time and over time. In so doing, our findings also add to performativity-inspired approaches to organizational theory (ibid) by capturing how various sociomaterial assemblages, supporting different knowledge, rules and assumptions and affording different practices or kinds of 'calculation' (Callon and Muniesa, 2005), may confront one another in their effort to support competing theories, often influencing their organizational outcomes. Sociomateriality can therefore help us understand how a theory may be able to shape routines, practices and boundaries and contribute to 'designing' an organization. Our evidence, in addition, also suggests that the organization itself might in return participate in 'designing' the theory.

\section{The mutual production of theory and organization}

Our final key finding concerns the mutual shaping of theory and organization. Our case study has highlighted the subtle ways in which modularity rules might be able to (re)configure the organization, its structure, practices and boundaries, while also shedding light over how, in turn, the situated enactment of modularity in this particular organization ended up modifying the theory. In the first case, concerning the influence of theory over organization, we have seen how the company's vision of modularity as an efficiency-seeking strategy aimed at standardizing and distributing products and 
organization and therefore supporting superior leanness and cost reduction, conflicted considerably with reliability, which instead demanded redundancy and the substantial overlap of production knowledge and activities.

In the second case, concerning the influence of the organization over theory, we have instead seen that, while modularity did manage to frame the rework process, at the same time it prompted the emergence of errors. These were readily enrolled by the competing rationale, reliability, which was able to win a marginal victory in the performative struggles between the two theories. This indicates that performing modularity had produced an extraordinarily lean and efficient organization, which was however brittle and fragile, and therefore prone to failure. The threat of failure, as highlighted and problematized by the supporters of the reliability argument, was considered to be such that it induced practitioners to revise their vision of modularity. As a consequence of the confrontation with reliability, modularity was modified. In capturing and theorizing the mutual shaping of theory and organization, this finding adds to both studies of modularity (Baldwin and Clark, 2000; Sanchez \& Mahoney, 1996; Brusoni et al., 2001; Brusoni and Prencipe, 2006) and wider approaches concerning the performativity of (organizational) theories (Cabantous et al., 2010; Cabantous and Gond, 2011).

Our findings beg a further and final question. Will the lessons from this outstanding organization, which had such a deep historical relationship with modularity, also succeed in modifying the wider theory, namely the scholarly debate surrounding modularity? While we are unable to predict any specific outcomes at this stage, we believe that it will depend upon the willingness of both the mainstream and the contingency sides of the modularity debate to engage with our results and novel approach which at the same time both reconciles and adds to existing approaches. It would be interesting, for example, if this outstanding organization which has initially sparked the academic interest towards modularity, would end up once again teaching us scholars some important theoretical lessons about the mutual shaping of theories and organizations.

Pushing our insights even further, we can foresee promising grounds for future investigation that may emerge from our novel approach. We envisage a new stream of studies investigating how the struggles among different (contradictory and complementary) theories or strategies, and their associated rules, rationales and logics, may play out and transform different organizational contexts. This would add to extant approaches which have focused on how different rationales or logics play out within the same theory (as in Cabantous and Gond's 2011 example of rational choice theory). Further advances that build on our framework might also include shedding new light over the emergence of macro theories and their organizational effects. Among the interesting features highlighted by our case evidence and related discussion, for example, is the hypothesis that the confrontation between modularity and reliability followed the unexpected emergence of tensions 
between two different (but usually complementary) sides of Lean Production theory, the 'efficiency', or 'cost reduction' side and the 'zero defects' side. Taking this insight further would prompt a timely investigation into the emergence of Lean Production as a meta-theory, incorporating both efficiency and reliability principles, albeit in different proportions. The question to arise then would be whether it was the imbalance created in our case by the overemphasis on the efficiency side of lean that brought two usually complementary features to clash irremediably. One possible answer, we posit, is that incorporating the errors and re-internalizing rework had the effect of temporarily restoring a truce between the two sides of this influential management theory, a truce which had been lost following the increasing emphasis on efficiency brought about by the electronics sector crisis.

While a comprehensive analysis of this topic lies beyond the scope of this paper, results indicate that our analytical framework based on performativity can contribute more generally towards advancing our understanding of fundamental aspects of contemporary organizing. In capturing the mutual constitution of multiple theories and organization, our approach begins to unravel the micro-level, sociomaterial mechanisms through which organizations are able to manage apparently unsolvable conflicts, contradictions and paradoxes (Poole and Van de Ven, 1989; Adler et al., 1999; Gibson and Birkinshaw, 2004) while dynamically adapting to change. Especially in tough and fast changing competitive environments, this crucial ability lies at the very basis of an organization's potential to survive and prosper. 


\section{References}

Adler P.S., Goldoftas B. and Levine D.I. (1999) Flexibility or efficiency? A case study of model changeovers in the Toyota production system. Organization Science 10: 43-67.

Akrich M. (1992) The De-Scription of Technical Objects. In: Bijker W.E., Law J. (eds) Shaping Technology/Building Society - Studies in Sociotechnical Change. Cambridge: MIT Press, 205-224. Appadurai A. (ed.) (1986) The Social Life of Things. Commodities in Cultural Perspective. New York: Cambridge University Press.

Austin J. (1962) How to do things with words. Cambridge, MA: Harvard University Press.

Baldwin C. Y., Clark K.B. (2000) Design Rules: Volume 1. The Power of Modularity. Cambridge: MIT Press.

Balogun J., Johnson G. (2004) Organizational Restructuring and Middle Manager Sensemaking. The Acad. of Management Journal 47: 523-549.

Barad K. (2003) Posthumanist Performativity: Toward an Understanding of How Matter Comes to Matter. Signs 28: 801-831.

Barad K. (2007) Meeting the University Halfway: Quantum Physics and the Entanglement of Matter and Meaning. Durham, NC: Duke University Press.

Bechky B.A. (2003) Sharing Meaning across Occupational Communities: The Transformation of Understanding on a Production Floor. Organization Science 14: 312-330.

Berg M., Timmermans S. (2000) Orders and Their Others: On the Constitution of Universalities in Medical Work. Configurations 8: 31-61.

Beunza D., Stark D. (2004) Tools of the trade: The sociotechnology of arbitrage in a Wall Street trading room. Industrial and Corporate Change 13: 369-400.

Beunza D., Hardie I. and MacKenzie D. (2006) A Price is a Social Thing: Towards a Material Sociology of Arbitrage. Organization Studies 27: 721-745.

Boland R.J., Tenkasi R.V. (1995) Perspective-making and perspective-taking in communities of knowing. Organization Science 6: 350-372.

Brusoni S., Prencipe A. and Pavitt K. (2001) Knowledge specialization, organization coupling, and the boundaries of the firm: Why do firms know more than they make? Administrative Science Quarterly 46: 597-625.

Brusoni S., Prencipe A. (2006) Making design rules: A multidomain perspective. Organization Science 17: 179-189.

Butler J. (1993) Bodies that matter. London: Routledge.

Cabantous L., Gond J.P. and Johnson-Cramer M. (2010) Decision Theory as Practice: Crafting Rationality in Organizations. Organization Studies 31: 1531-1566.

Cabantous L. and Gond P. (2011) Rational Decision Making as Performative Praxis: Explaining Rationality's Éternel Retour. Organization Science 22: 573-586.

Cabantous L., Gond J. and Millo Y. (2014) EGOS Colloquium Sub-theme 43: Performativity as Politics: Rethinking Performativity and Power Dynamics.

Callon M. (1986) Some Elements of a Sociology of Translation: Domestication of the Scallops and the Fishermen of St Brieuc Bay. In: Law J. (ed.) Power, Action and Belief: A New Sociology of Knowledge. London: Routledge, 196-229.

Callon M. (1998) An essay on framing and overflowing: economic externalities revisited by sociology. In: Callon M. (ed.) The Laws of the Markets. Oxford: Blackwell: 244-269.

Callon M. (2007) What Does It Mean To Say That Economics Is Performative? In: MacKenzie D., Muniesa F. and Siu L. (eds), Do Economists Make Markets? On the Performativity of Economics. Oxford: Princeton University Press, $311-357$.

Callon M., Caliskan C. (2010) Economization, Part 2: A Research Programme on the Study of Marketization. Economy and Society 39: 1-32. 
Callon M. and Muniesa F. (2005) Economic markets as calculative collective devices. Organization Studies 26:1129-1250.

Campagnolo D. and Camuffo A. (2009) The concept of modularity within the management studies: a literature review. International Journal of Management Reviews 12(3): 259 - 283.

Carlile P. (2004) Transferring, Translating, and Transforming: An Integrative Framework for Managing Knowledge Across Boundaries. Organization Science 15: 555-568.

Chandler A. D. (1977) The visible hand. Cambridge: Belknap.

Chesbrough H.V. and Kusunoki K. (2001) The Modularity Trap: Innovation, Technology Phase Shifts and the Resulting Limits of Virtual Organizations. London: Sage Publications.

Chesbrough H.W. (2003) Towards a Dynamics of Modularity. A Cyclical Model of Technical Advance. In: Prencipe A., Davies A. and Hobday M. (eds) The Business of Systems Integration. Oxford: Oxford University Press, 174-198.

D'Adderio L. (2008) The performativity of routines: Theorising the influence of artefacts and distributed agencies on routine dynamics. Research Policy 37(5): 769-789.

Darr A. and Pinch T. (2013) Performing Sales: Material Scripts and the Social Organization of Obligation. Organization Studies 34(11): 1601-1621.

Dougherty D. (1992) Interpretive Barriers to Successful Product Innovation in Large Firms. Organization Science 3: 179-202.

Feldman M.S. and Orlikowski W. (2011) Theorizing Practice and Practicing Theory. Organization Science 22: 1240-1253.

Ferraro F., Pfeffer J. and Sutton R.I. (2005) Economics language and assumptions: how theories can become self-fulfilling. Academy of Management Review 30: 8-24.

Fleming L. and Sorenson O. (2001) The dangers of modularity. Harvard Business Review 79: 20- 21.

Gibson C.B. and Birkinshaw J. (2004) The Antecedents, Consequences, and Mediating Role of Organizational Ambidexterity. The Academy of Management Journal 47: 209-226.

Glaser B. and Strauss A. (1967) The Discovery of Grounded Theory: Strategies of Qualitative Research. London: Wiedenfeld \& Nicholson.

Greenwood R., Raynard M., Kodeih F., Micelotta E. R. and Lounsbury M. (2011) Institutional complexity and organizational responses. The Academy of Management Annals 5: 317-371.

Henderson R.M. and Clark K.B. (1990). Architectural Innovation: The Reconfiguration of Existing Product Technologies and the Failure of Established Firms. Administrative Science Quarterly 35: 930.

Hobday M., Davies A. and Prencipe A. (2005) Systems integration: a core capability of the modern corporation. Industrial and Corporate Change 14: 1109-1143.

Krippendorff K. (2004) Content analysis: An introduction to its methodology (2nd ed.). Thousand Oaks, CA: Sage.

Langley A. (1999) Strategies for Theorizing from Process Data. The Academy of Management Review 24: 691-710.

Langley A. and Tsoukas H. (2010) Introducing 'Perspectives on Process Organization Studies'. In: Hernes T. and Maitlis S. (eds) Perspectives on Process Organization Studies. Oxford: Oxford University Press, 1-26.

Langlois R.N. (2002) Modularity in technology and organization. Journal of Economic Behavior and Organization 49(1): 19-37.

Langlois R.N. (2003) The vanishing hand: the changing dynamics of industrial capitalism. Industrial and Corporate Change 12: 351-385.

LaPorte T.R. and Consolini P. (1991) Working in practice but not in theory Theoretical challenges in high reliability organizations. Journal of Public Administration Research and Theory 1: 19-47.

Laprie J. C. (ed.) (1992) Dependability: Basic Concepts and Terminology. Vienna: Springer. 
Latour B. (1987) Science in Action: How to Follow Scientists and Engineers through Society. Cambridge, MA: Harvard University Press.

Latour B. (1993) The pasteurization of France. Cambridge, MA: Harvard University Press.

MacKenzie D. (2006) An Engine, not a camera: How Financial Models Shape Markets. Cambridge, MA: MIT Press.

MacKenzie D. and Millo Y. (2003) Constructing a market, performing a theory: the historical sociology of a financial derivatives exchange. American Review of Sociology 109: 107-145.

MacKenzie D., Muniesa F. and Siu L. (eds) (2007) Do Economists Make Markets? On the Performativity of Economics. Oxford: Princeton University Press.

MacKenzie D. (2009) Material markets: How economic agents are constructed. Oxford: Oxford University Press.

March J. G. (1991) Exploration and exploitation in organizational learning. Organization Science 2: 71-87.

March J. and Simon H.(1958) Organizations. New York: Wiley.

Marengo L., Pasquali C. and Valente M. (2005) Decomposability and modularity of economic interactions. In: Callebaut W. and Rasskin-Gutman D. (eds) Modularity: understanding the development and evolution of complex natural systems. Cambridge, MA: MIT Press, 835-897.

Mol A. (2005) The body multiple: Ontology in Medical Practice. Durham: Duke University Press.

Narduzzo A., Rocco E. and Warglien M. (2000) Talking about Routines in the Field: the Emergence of Organizational Capabilities in a New Cellular Phone Network Company. In: Dosi G., Nelson R.R. and Winter S. G. (eds) The nature and dynamics of organizational capabilities. New York: Oxford University Press, 27-50.

Nag R., Corley K. G. and Gioia D. A. (2007) The intersection of organizational identity, knowledge, and practice: Attempting strategic change via knowledge grafting. Academy of Management Journal 50: 821-847.

Nelson R. R. and Winter S.G. (1982) An evolutionary theory of economic change. Cambridge, MA: Belknap Press.

Orlikowski W.J. and Scott S.V. (2008) Sociomateriality: Challenging the Separation of Technology, Work and Organization. The Academy of Management Annals 2: 433-474.

Orr J.E. (1990) Sharing Knowledge, Celebrating Identity: War Stories and Community Memory in a Service Culture. In: Middleton D. S. and Edwards D. (eds) Collective Remembering: Memory in Society. Beverley Hills: Sage Publications.

Orton J.D. and Weick K.E. (1990) Loosely Coupled Systems: A Reconceptualization. Academy of Management Review 15: 203-223.

Parnas D. L., Clements P.C. and Weiss D.M. (1985) The modular structure of complex systems. IEEE Transactions on Software Engineering 11: 259-266.

Pentland B.T. (1992) Organizing moves in software support hotlines. Administrative Science Quarterly 37: 527- 548.

Pentland B.T. and Feldman M. (2008) Designing routines: On the folly of designing artifacts, while hoping for patterns of action. Information and Organizations 18: 235-250.

Pickering A. (1995) The Mangle of Practice: Time, Agency and Science. Chicago: University of Chicago Press.

Pollock N. and Williams R.A. (2009) Software and organisations: The biography of the enterprisewide system or how SAP conquered the world. Abingdon: Routledge.

Poole M. S. and Van de Ven A. (1989) Using paradox to build management and organizational theory. Academy of Management Review 14: 562-578. 
Purdy J.M. and Gray B. (2009) Conflicting logics, mechanisms of diffusion and multilevel dynamics in emerging institutional fields. Academy of Management Journal 52: 355-380.

Rerup C. and Feldman M. (2011) Routines as a source of change in organizational schemata: The role of trial-and-error learning. Academy of Management Journal 54( 3): 577-610.

Roberts K.H. (1990) Characteristics of One Type of High Reliability Organization. Organization Science 1: 160-176.

Rousseau D. M., Sitkin S.B., Burt R.S. and Camerer C. (1998) Not So Different After All: A CrossDiscipline View of Trust. Academy of Management Review 23: 393- 404.

Russell A.L. (2012) Modularity: An Interdisciplinary History of an Ordering Concept. Information and Culture 47(3): 257-287.

Sanchez R. and Mahoney J.T. (1996) Modularity, flexibility, and knowledge management in product and organization design. Strategic Management Journal 17: 63-76.

Schatzki T. R., Knorr Cetina K. and von Savigny E.. (eds) (2001) The Practice Turn in Contemporary Theory. London: Routledge.

Schilling M. (2000) Toward a General Modular Systems Theory and Its Application to Interfirm Product Modularity. Academy of Management Review 25: 312-335.

Siggelkow N. (2007) Persuasion with case studies. Academy of Management Journal 50(1): 20-24.

Simon H. (1962) The Architecture of Complexity. Proceedings of the American Philosophy Society 106: 467-482.

Simon H. (1996) The Sciences of the Artificial. 3rd Ed. Boston: MIT Press.

Soanes C. and Stevenson A. (2005) Oxford Dictionary of English. Second edition, revised. Oxford: Oxford University Press.

Suddaby R. (2006) What grounded theory is not. Academy of Management Journal 49: 633-642.

Strauss A. and Corbin J. (1990) Basics of qualitative research. Newbury Park, CA: Sage.

Sturgeon T. J. (2002) Modular production networks: a new American model of industrial organization. Industrial and Corporate Change 11: 451-496.

Suchman L. (1987). Plans and situated action: The problem of human-machine interaction. Cambridge: Cambridge University Press.

Takeishi A. (2002) Knowledge Partitioning in the Inter-Firm Division of Labor: The Case of Automotive Product Development. Organization Science 13: 321-338.

Ulrich K.T. and Eppinger S.D. (1995). Product Design and Development. New York: McGraw Hill. US Defence Report (2003) - Company Confidential.

Van Maanen J. (1979) The fact of fiction in organizational ethnography. Administrative Science Quarterly 24: 539-550.

Vaughan D. (1996) The Challenger launch decision. Chicago: University of Illinois Press.

Weick K.E. (1979) The social psychology of organizing. Reading, MA: Addison Wesley.

Weick K.E. and Roberts K.H. (1993). Collective mind in organizations: Heedful interrelating on flight decks. Administrative Science Quarterly 38: 357-81.

Weick K. E. and Sutcliffe K.M. (2001) Managing the Unexpected. San Francisco, CA: Jossey-Bass.

Weick K.E., Sutcliffe K.M. and Obstfeld D. (1999) Organizing for high reliability: Processes of collective mindfulness. In: Staw B.M. and Sutton R. (eds), Research in organizational behavior 23, 81-123. Greenwich, CT: JAI Press. 
West J. (2003) How open is open enough? Melding proprietary and open source platform strategies. Research Policy 32: 1259-1285.

Womack J. P. and Jones D. T. (1996) Lean Thinking. New York: Simon \& Schuster. 
Figure 1 - Computer board rework and repair process
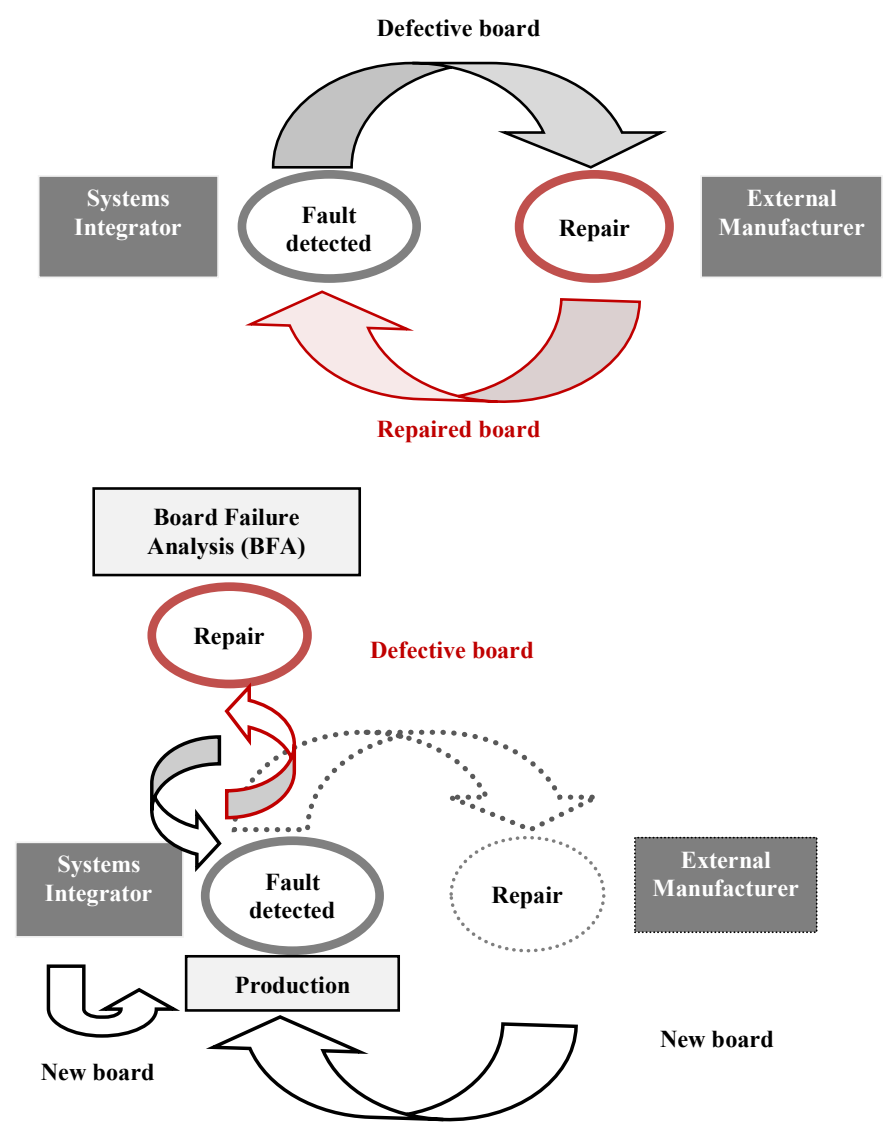

Figure 1a: in-house rework

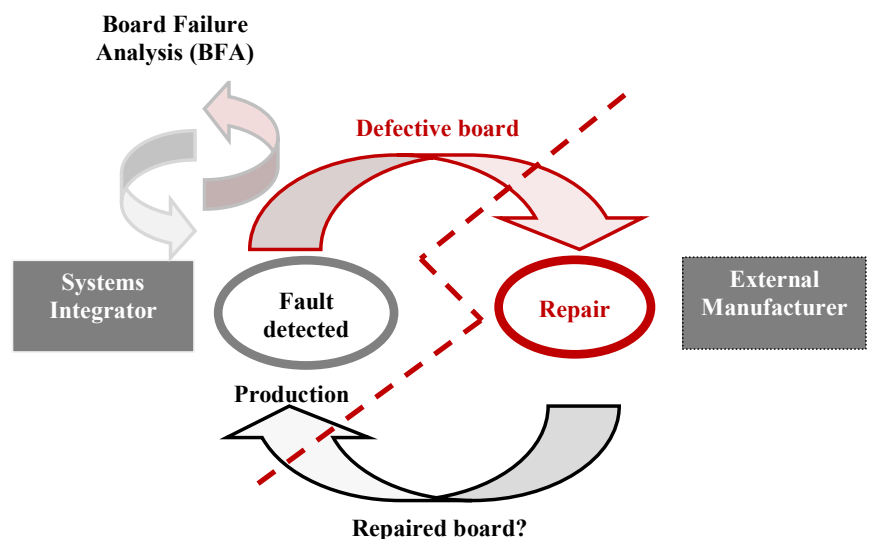

Figure 1b: rework outsourced

Figure 2 - Theoretical Framework

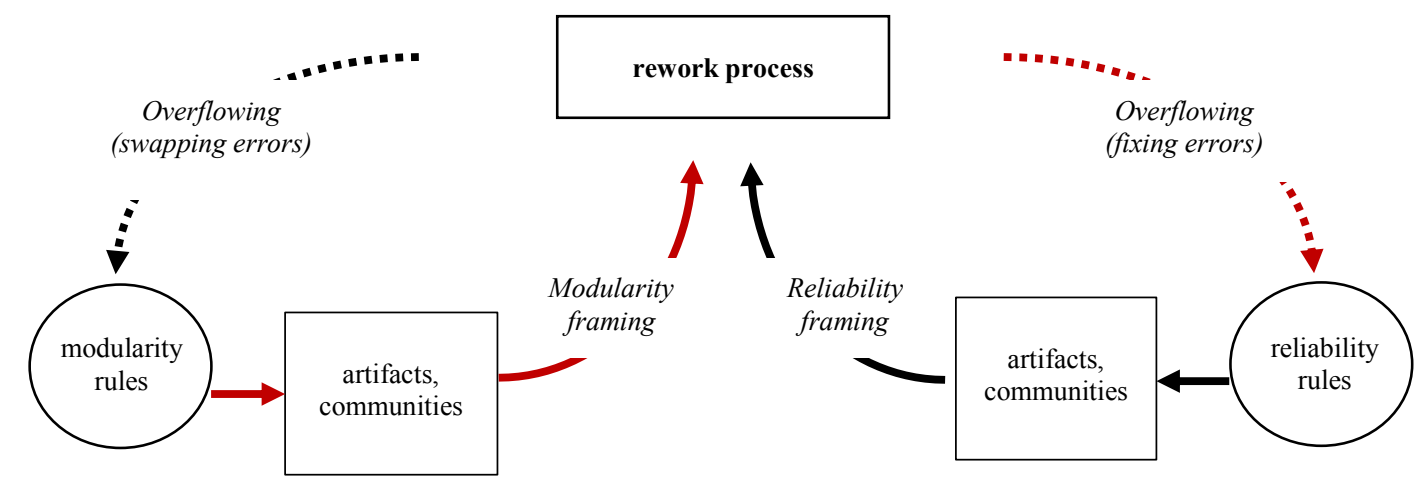


Table 1 Modularity and Reliability Rules (framing) and their Errors (overflowing)

\begin{tabular}{|c|c|c|}
\hline \multirow{3}{*}{$\begin{array}{l}\text { RESERIALISING/ } \\
\text { LOSS OF IDENTITY }\end{array}$} & \multicolumn{2}{|c|}{ 'Fixing' (performing reliability) vs. 'Swapping' (performing modularity) } \\
\hline & Rule & $\begin{array}{l}\text { Swapping. No need for coordination. Modular systems 'hide information' } \\
\text { behind standardized interfaces so that the component's internal characteristics } \\
\text { can be overlooked (Parnas et al. 1985; Baldwin \& Clark, 2001; Sanchez \& } \\
\text { Mahoney 1996; Schilling 2000; Sturgeon 2002; Langlois 2002). }\end{array}$ \\
\hline & Error & $\begin{array}{l}\text { Fixing. Loss of memory, failure history, loss of traceability, no learning } \\
\text { (Fixing => emphasis on "continuous learning") (Weick et al. 1999) }\end{array}$ \\
\hline \multirow[t]{3}{*}{$\begin{array}{l}\text { ZERO INVENTORY/ } \\
\text { AUTOSWAP }\end{array}$} & Rule & $\begin{array}{l}\text { Swapping. Full component interchangeability, 'mix and match'. Clear } \\
\text { standardization and decoupling of components within a system means that } \\
\text { these can be swapped and substituted straightforwardly (Sanchez \& Mahoney } \\
\text { 1996) }\end{array}$ \\
\hline & & No slack, 'zero inventory’ (Womack \& Jones 1996) \\
\hline & Error & $\begin{array}{l}\text { Fixing. No redundancy, combined with swapping means no tracking and } \\
\text { tracing (Fixing => acknowledging the role of slack, redundancy) (Weick et al. } \\
\text { 1999) }\end{array}$ \\
\hline \multirow{2}{*}{$\begin{array}{l}\text { PROBLEM } \\
\text { OWNERSHIP/ } \\
\text { RESPONSIBILITY }\end{array}$} & Rule & $\begin{array}{l}\text { Swapping. No need to take ownership of/responsibility for failure "shifting the } \\
\text { problem" }\end{array}$ \\
\hline & Error & $\begin{array}{l}\text { Fixing. Losing track of failures, shifting the problem (Fixing=> "owning the } \\
\text { problem", emphasis on "heed" "attention" and "care") (Roberts 1990; Weick } \\
\text { \& Roberts 1993) }\end{array}$ \\
\hline \multirow{2}{*}{$\begin{array}{l}\text { SHARP DIV OF LAB/ } \\
\text { ASYMMETRIC VIEWS/ } \\
\text { UNEVEN ACCESS TO } \\
\text { TOOLS }\end{array}$} & Rule & $\begin{array}{l}\text { Swapping. Sharp division of productive labor (Sanchez \& Mahoney 1996). } \\
\text { Outsourcing allows systems integrator to relinquish ownership and } \\
\text { responsibility for subcontracted components. Separation of component from } \\
\text { system testing }\end{array}$ \\
\hline & Error & $\begin{array}{l}\text { Fixing. Unable to fault find (Fixing => coordination through "shared } \\
\text { ideology" or "mindsets", "collective mindfulness") (Weick at el. 1999; } \\
\text { Vaughan 1996) }\end{array}$ \\
\hline \multirow{2}{*}{$\begin{array}{l}\text { ARM'S LENGTH } \\
\text { RELATIONSHIP }\end{array}$} & Rule & $\begin{array}{l}\text { Swapping. Market-like, arm’s length relationship with suppliers (Langlois } \\
\text { 2002) }\end{array}$ \\
\hline & Error & $\begin{array}{l}\text { Fixing. Not being able to know if the fault has been fixed (Fixing => } \\
\text { emphasis on coordination, collaboration, trust, "collegiality") (Rousseau et al. } \\
\text { 1998, LaPorte \& Consolini 1993), preoccupation with failure (Weick \& } \\
\text { Sutcliffe 2001) }\end{array}$ \\
\hline \multirow[t]{2}{*}{$\begin{array}{l}\text { JUDGEMENT \& } \\
\text { PROBLEM SOLVING }\end{array}$} & Rule & $\begin{array}{l}\text { Swapping. Elimination of uncertainty, ambiguity, judgment in problem- } \\
\text { solving. A modular organization is "[...] one in which tasks and } \\
\text { responsibilities are distributed across separate groups/units, which do not } \\
\text { engage in ongoing, real-time communication and joint problem solving" } \\
\text { (Carliss Baldwin, personal communication). In fully modular systems, } \\
\text { interactions among components and overall system behavior entirely } \\
\text { predictable, process of assembling components into a functioning system } \\
\text { reduced to simple Lego-like activity. }\end{array}$ \\
\hline & Error & $\begin{array}{l}\text { Fixing. Fragmented problem-solving (Fixing=> joint problem solving by } \\
\text { teams of experts, reluctance to simplify interpretations, Weick \& Sutcliffe } \\
\text { 2001) }\end{array}$ \\
\hline \multirow[t]{2}{*}{$\begin{array}{l}\text { FORMAL \& } \\
\text { INFORMAL RULES, } \\
\text { PROCEDURES }\end{array}$} & Rule & $\begin{array}{l}\text { Swapping. Clear and sharp division of knowledge and capabilities across the } \\
\text { integrator/supplier boundaries (Sanchez \& Mahoney 1996; Ulrich \& Eppinger } \\
\text { 1995). Loosely-coupled modular system (Orton \& Weick 1990) no need to } \\
\text { fault-find (exploitation). Formal and informal procedures support automatic } \\
\text { switching and shifting responsibility to suppliers }\end{array}$ \\
\hline & Error & $\begin{array}{l}\text { Fixing. Unable to know for certain the cause of failure (Fixing => "zero } \\
\text { tolerance" on errors, Failure is Not An Option) (exploration) }\end{array}$ \\
\hline \multirow{2}{*}{$\begin{array}{l}\text { SYSTEMIC } \\
\text { INTERACTIONS }\end{array}$} & Rule & $\begin{array}{l}\text { Fixing. Need for understanding systemic interdependencies, need for systems } \\
\text { integration (Brusoni et al. 2001; Hobday et al. 2005) }\end{array}$ \\
\hline & Error & $\begin{array}{l}\text { Rapid, uneven innovation (Nelson \& Winter 1982) destabilizes server system } \\
\text { Swapping. Unable to unproblematically switch boards in a system (Swapping } \\
\text { => no need for system testing (Sanchez \& Mahoney 1996) }\end{array}$ \\
\hline
\end{tabular}

